06

\title{
Модификация пористого углеродного материала полимерным комплексом кобальта с основанием Шиффа саленового типа для электродов электрохимических суперконденсаторов
}

\author{
(С) Ю.А. Положенцева, М.В. Новожилова, В.А. Быков, М.П. Карушев \\ Физико-технический институт им. А.Ф. Иофффе РАН, Санкт-Петербург, Россия \\ ๑ E-mail: mkarushev@mail.ioffe.ru
}

Поступило в Редакцию 29 мая 2020 г.

В окончательной редакции 15 июня 2020г.

Принято к публикации 15 июня 2020 г.

\begin{abstract}
Исследовано влияние модификации пористого углеродного материала, используемого для производства суперконденсаторов, полимерным комплексом кобальта с основанием Шиффа саленового типа на емкость материала. Способность этих полимеров к многоэлектронным редокс-процессам в сочетании с предложенной эффективной технологией модификации позволила повысить емкость электродов в 2.4 раза по сравнению с емкостью немодифицированных углеродных электродов. Удельная емкость полимера поли$\left[\mathrm{Co}\left(\mathrm{CH}_{3} \mathrm{OSaltmen}\right)\right]$ при плотности нанесения полимера $1.3 \mathrm{mg} \cdot \mathrm{cm}^{-2}$ составила $170 \mathrm{~mA} \cdot \mathrm{h} \cdot \mathrm{g}^{-1}$.
\end{abstract}

Ключевые слова: проводящий металлополимер, основание Шиффа, суперконденсатор.

DOI: 10.21883/PJTF.2020.18.49998.18403

Электрохимические двойнослойные суперконденсаторы (ЭДСК) - практически важная электрохимическая энергетическая система, способная обеспечить высокую удельную мощность. Удельные характеристики ЭДСК в основном определяются свойствами используемых материалов. В качестве активных материалов электродов в подавляющем большинстве устройств используются углеродные материалы с большой удельной поверхностью. Развитие таких систем ограничено удельной емкостью используемых материалов, причем очевидно, что предел наращивания поверхности, а следовательно, и емкости углеродных материалов фактически достигнут [1]. Эффективным методом повышения энергии ЭДСК является модификация поверхности углеродных материалов веществами, способными к обратимому электрохимическому окислению в области потенциалов функционирования электродов в ЭДСК. Среди проводящих полимеров в качестве подобного рода модификаторов были исследованы полианилин [2,3], полипиррол [4,5] и полиэтилендиокситиофен [6], которые обладают быстрой кинетикой заряда-разряда и низкой стоимостью $[2,4]$. Однако органические проводящие полимеры характеризуются недостаточно большой удельной емкостью и недостаточной стабильностью при многократном заряде-разряде [6]. Другой тип полимеров, которые могут быть использованы в качестве модификатора, - полимерные комплексы переходных металлов с основаниями Шиффа [7,8]. Эти полимеры обладают рядом свойств, которые позволяют применять электроды, модифицированные полимерными комплексами, в энергозапасающих системах, а именно способностью к обратимому электрохимическому окислению и восстановлению в широком диапазоне потенциалов [9], хорошей удельной емкостью и высокой скоро- стью транспорта заряда $[10,11]$, уникальной термической стабильностью [12].

Полимерные комплексы никеля успешно применяются для модификации нанопористых углеродных материалов (они увеличивают емкость положительного электрода при сохранении емкости двойного электрического слоя углеродного материала) и демонстрируют способность к многократному повторению циклов зарядаразряда без потери емкости [13-15].

Недавние исследования показали, что полимерные комплексы кобальта с основаниями Шиффа способны к многоэлектронным редокс-превращениям с участием как металлического центра, так и органической части молекулы [16]. Полимеризация таких комплексов происходит с образованием новых связей $\mathrm{C}-\mathrm{C}$ между пара-положениями (по отношению к феноксильному кислороду) лигандных колец. Окисление (в том числе электрохимическое) приводит к образованию бифеноксильных катион-радикалов (первая стадия) и дикатионов (вторая стадия). В случае полимерных комплексов кобальта двум лиганд-центрированным стадиям предшествует металл-центрированный редокс-процесс $\mathrm{Co}(\mathrm{II}) / \mathrm{Co}(\mathrm{III})$. Электрохимическое допирование (окисление) таких проводящих пленок сопровождается входом в пленку анионов электролита для компенсации возникающего в пленке объемного заряда. За счет участия металлического центра в редокс-процессах удельная емкость полимерных комплексов с кобальтовым металлическим центром значительно превосходит емкость никелевых полимерных комплексов. Это открывает потенциальную возможность улучшения функциональных характеристик полимер-модифицированных суперконденсаторов.

Настоящая публикация посвящена разработке электродов для ЭДСК на основе пористого углеродно- 


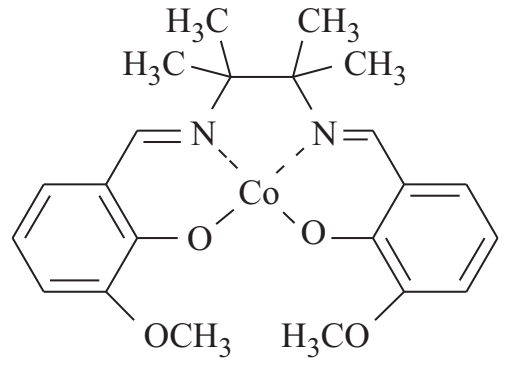

Рис. 1. Молекулярная структура комплекса $\left[\mathrm{Co}\left(\mathrm{CH}_{3} \mathrm{OSaltmen}\right)\right]$.

го материала, модифицированного полимерным комплексом кобальта с лигандом саленового типа поли$\left[\mathrm{Co}\left(\mathrm{CH}_{3} \mathrm{OSaltmen}\right)\right]$. Строение использованного мономерного комплекса показано на рис. 1. Разрядные характеристики модифицированных электродов сопоставлялись с аналогичными параметрами немодифицированных электродов.

Электрохимические измерения электродов проводились по трехэлектродной схеме с использованием потенциостата-гальваностата Epsilon (BAS) в $1 \mathrm{M}$ растворе тетрафторборат тетраэтиламмония $\left(\mathrm{Et}_{4} \mathrm{~N}\right) \mathrm{BF}_{4}$ в ацетонитриле (Криохром, марка 0) (АН). Вспомогательный электрод был изготовлен из высокопористого углеродного материала, его геометрические размеры превышают размеры рабочего электрода. В качестве электрода сравнения использовался неводный электрод MF-2062 $(\mathrm{BASi})-0.005 \mathrm{M} \mathrm{Ag}^{+} / \mathrm{Ag}$ в $0.1 \mathrm{M}\left(\mathrm{Et}_{4} \mathrm{~N}\right) \mathrm{BF}_{4} / \mathrm{AH}$ (потенциал относительно хлорид-серебряного электрода, заполненного насыщенным водным раствором хлорида натрия, $-0.3 \mathrm{~V}$, далее все потенциалы приведены относительно хлорид-серебряного электрода).

Электроды с размером поверхности $10 \times 10 \mathrm{~mm}$ были изготовлены из высокопористого углеродного материала с удельной поверхностью $1700 \mathrm{~m}^{2} \cdot \mathrm{g}^{-1} \quad$ (EnerG2 Technologies, Inc.). Модификация поверхности проводилась по методике, представленной в работе [15], синтезированным мономерным комплексом кобальта с основанием Шиффа саленового типа [Co $\left.\left(\mathrm{CH}_{3} \mathrm{OSaltmen}\right)\right]$ [17]. Полимеризация предварительно адсорбированного комплекса проходила путем гальваностатической поляризации электрода при плотности тока $25 \mathrm{~mA} \cdot \mathrm{cm}^{-2}$ от равновесного потенциала до потенциала $1.5 \mathrm{~V}$ в $1 \mathrm{M}$ растворе $\left(\mathrm{Et}_{4} \mathrm{~N}\right) \mathrm{BF}_{4}$ (Aldrich) в $\mathrm{AH}$ с последующей потенциостатической поляризацией электрода при $1.5 \mathrm{~V}$ в течение $120 \mathrm{~s}$ (рис. 2). На зарядной кривой электрода с адсорбированным комплексом при потенциалах $>0.6 \mathrm{~V}$ происходит значительное отклонение от характерной для инертного электрода прямо пропорциональной зависимости потенциала от пропущенного заряда. Наблюдаемое отклонение объясняется электрохимическим окислением адсорбированного комплекса, в конечном счете приводящим к его полимеризации и иммобилизации на высокоразвитой поверхности углеродного материала. После электроокислительной полимеризации адсорбированного комплекса электрод гальваностатически разряжался при плотности тока $2.5 \mathrm{~mA} \cdot \mathrm{cm}^{-2}$ до потенциала $0 \mathrm{~V}$ и промывался чистым ацетонитрилом. Масса полимера определялась по увеличению массы электрода после электрохимической полимеризации и промывки и составила $1.3 \mathrm{mg} \cdot \mathrm{cm}^{-2}$.

На рис. 3 приведены разрядные кривые немодифицированного электрода (1) и электрода, модифицированного полимерным комплексом поли- $\left[\mathrm{Co}\left(\mathrm{CH}_{3}\right.\right.$ OSaltmen $\left.)\right]$ (2), при токе разряда $2.5 \mathrm{~mA} \cdot \mathrm{cm}^{-2}$ в диапазоне потенциалов 1.4-0 V. Разрядная кривая немодифицированного электрода линейна, что характерно для разряда двойного электрического слоя на поверхности углеродного материала электрода. В области потенциалов $0-0.15 \mathrm{~V}$ для обоих электродов наблюдаются параллельные участки,

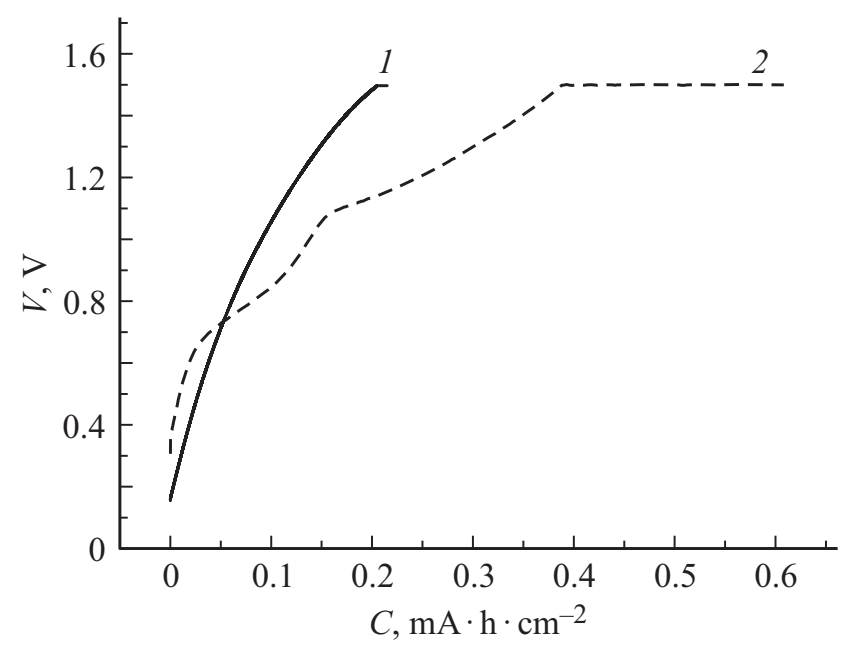

Рис. 2. Зарядные кривые немодифицированного электрода (1) и электрода с адсорбированным комплексом $\left[\mathrm{Co}\left(\mathrm{CH}_{3}\right.\right.$ OSaltmen $\left.)\right](2)$ при токе $25 \mathrm{~mA} \cdot \mathrm{cm}^{-2}$.

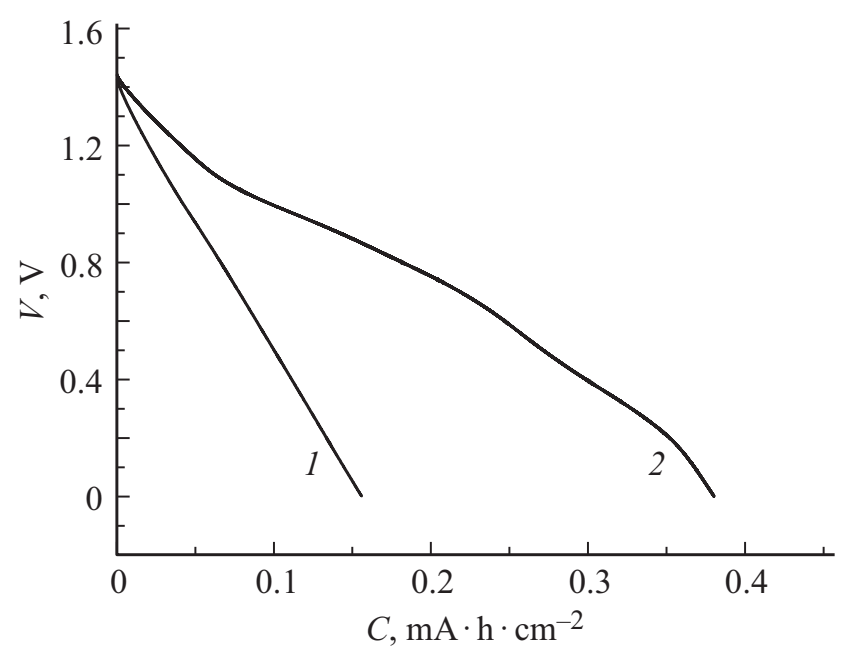

Рис. 3. Разрядные кривые немодифицированного электрода (1) и электрода, модифицированного полимерным комплексом $\left[\mathrm{Co}\left(\mathrm{CH}_{3} \mathrm{OSaltmen}\right)\right](2)$, при токе $2.5 \mathrm{~mA} \cdot \mathrm{cm}^{-2}$. 
свидетельствующие о неизменности емкости двойного электрического слоя углеродного материала после модификации. В диапазоне потенциалов $0.15-1.4 \mathrm{~V}$ модифицированный электрод обладает большей емкостью, так как в этом диапазоне наблюдается электрохимическая активность полимера поли-[Co( $\left.\left.\mathrm{CH}_{3} \mathrm{OSaltmen}\right)\right]$ [17] и, помимо разряда двойного электрического слоя, происходит фарадеевский процесс с участием полимерного комплекса. Емкость модифицированного электрода в сравнении с емкостью немодифицированного увеличилась в 2.4 раза.

Также практически важным параметром, оказывающим влияние на эксплуатационные характеристики суперконденсаторов, является сопротивление электрода. Его можно рассчитать исходя из величины начального падения напряжения при разряде. Важно отметить, что сопротивление электрода, модифицированного полимерным комплексом, не изменилось по сравнению с сопротивлением немодифицированного электрода.

По отношению прироста емкости электрода и массы полимера было рассчитано значение удельной емкости полимера, составившее $170 \mathrm{~mA} \cdot \mathrm{h} \cdot \mathrm{g}^{-1}$. Полученное значение соответствует ранее опубликованному значению емкости, рассчитанному по вольт-амперным характеристикам тонких пленок аналогичного полимера и массам тонких пленок, полученных методом кварцевой микрогравиметрии $\left(182 \mathrm{~mA} \cdot \mathrm{h} \cdot \mathrm{g}^{-1}\right)$ [16], и отвечает обратимому переносу трех электронов на фрагмент при окислении-восстановлении полимера.

Таким образом в работе показано, что модификация высокопористого углеродного материала электродов полимерным комплексом кобальта с основанием Шиффа приводит к значительному увеличению емкости по сравнению с емкостью немодифицированных электродов и дает потенциальную возможность применения таких электродов в гибридных суперконденсаторах.

\section{Конфликт интересов}

Авторы заявляют, что у них нет конфликта интересов.

\section{Список литературы}

[1] Kumar Y., Rawal S., Joshi B., Hashmi S.A. // J. Solid State Electrochem. 2019. V. 23. P. 667-692. DOI: $10.1007 / \mathrm{s} 10008-018-4160-3$

[2] Liu P., Yan J., Guang Z., Huang Y., Li X., Huang W. // J. Power Sources. 2019. V. 424. P. 108-130. DOI: 10.1016/j.jpowsour.2019.03.094

[3] Eftekhari A., Li L., Yang Y. // J. Power Sources. 2017. V. 347. P. 86-107. DOI: 10.1016/j.jpowsour.2017.02.054

[4] Afzal A., Abuilaiwi F.A., Habib A., Awais M., Waje S.B., Atieh M.A. // J. Power Sources. 2017. V. 352. P. 174-186. DOI: 10.1016/j.jpowsour.2017.03.128

[5] Huang Y., Li H., Wang Z., Zhu M., Pei Z., Xue Q., Huang Y., Zhi C. // Nano Energy. 2016. V. 22. P. 422-438. DOI: 10.1016/j.nanoen.2016.02.047
[6] Nabilah Azman N.H., Lim H.N., Sulaiman Y. // Electrochim. Acta. 2016. V. 188. P. 785-792. DOI: $10.1016 /$ j.electacta.2015.12.019

[7] Li J., Gao F., Zhang Y., Kang F., Wang X., Ye F., Yang J. // Sci. China Chem. 2012. V. 55. P. 1338-1344. DOI: $10.1007 / \mathrm{s} 11426-012-4585-\mathrm{y}$

[8] Guo P., Hui T.-W., Cheung K.-C., Wong K.-Y., Shiu K.-K. // J. Electroanal. Chem. 2001. V. 498. P. 142-151. DOI: $10.1016 / \mathrm{S} 0022-0728(00) 00347-8$

[9] Dmitrieva E., Rosenkranz M., Danilova J.S., Smirnova E.A., Karushev M.P., Chepurnaya I.A., Timonov A.M. // Electrochim. Acta. 2018. V. 283. P. 1742-1752. DOI: $10.1016 /$ j.electacta.2018.07.131

[10] Levin O.V., Karushev M.P., Timonov A.M., Alekseeva E.V., Zhang S., Malev V.V. // Electrochim. Acta. 2013. V. 109. P. 153-161. DOI: 10.1016/j.electacta.2013.07.070

[11] Alekseeva E.V., Chepurnaya I.A., Malev V.V., Timonov A.M., Levin O.V. // Electrochim. Acta. 2017. V. 225. P. 378-391. DOI: $10.1016 /$ j.electacta.2016.12.135

[12] Новожсилова М.В., Смирнова Е.А., Карушев М.П., Тимонов А.М., Малев В.В., Левин О.В. // Электрохимия. 2016. T. 52. № 12. C. 1324-1332. DOI: $10.7868 / \mathrm{S} 0424857016120100$

[13] Li J., Gao F., Zhang Y., Wang X. // Chin. J. Polym. Sci. 2010. V. 28. P. 667-671. DOI: 10.1007/s10118-010-0083-x

[14] Чепурная А., Логвинов С.А., Карушев М.П., Тимонов А.М., Малев В.В. // Электрохимия. 2012. Т. 48. № 5. С. 590-598.

[15] Карушев М.П., Тимонов А.М. // ЖПХ. 2012. Т. 85. В. 6. C. 932-938.

[16] Novozhilova M.V., Smirnova E.A., Polozhentseva J.A., Danilova J.S., Chepurnaya I.A., Karushev M.P., Malev V.V., Timonov A.M. // Electrochim. Acta. 2018. V. 282. P. 105-115. DOI: $10.1016 /$ j.electacta.2018.06.030

[17] Holm R.H., Everett G.W., Jr., Chakravorty A. // Prog. Inorgan. Chem. 1966. V. 7. P. 83-214. DOI: $10.1002 / 9780470166086 . c h 3$ 